\title{
Metabolic Syndrome: Epidemiological, Clinical and Biological Profiles in the Cardiology and Internal Medicine Departments of the Mother-Child CHU “Luxembourg”
}

\author{
Asmaou Keita1, Boubacar Sonfo ${ }^{2}$, Sanoussi Daffé1, Daouda Fofana1, Coumba Thiam², \\ Oumar Doucouré1, Souleymane Diallo1, Mariam Sako ${ }^{3}$, Massama Konaté4, Hamidou Omar Bâ5, \\ Youssouf Camara², Ibrahima Sangaré5, Souleymane Coulibaly³, Ichaka Menta ${ }^{5}$, \\ Mamadou Bocary Diarra1
}

${ }^{1}$ Cardiology Department of CHU Mère-Enfant, Bamako, Mali

${ }^{2}$ Cardiology Department of CHU Kati, Bamako, Mali

${ }^{3}$ Cardiology Department of CHU Point G, Bamako, Mali

${ }^{4}$ Internal Medicine Department, Mali Hospital, Bamako, Mali

${ }^{5}$ Cardiology Department of CHU Gabriel Touré, Bamako, Mali

Email: *sonfo20032001@yahoo.fr

How to cite this paper: Keita, A., Sonfo, B., Daffé, S., Fofana, D., Thiam, C., Doucouré, O., Diallo, S., Sako, M., Konaté, M., Bâ, H.O., Camara, Y., Sangaré, I., Coulibaly, S., Menta, I. and Diarra, M.B. (2021) Metabolic Syndrome: Epidemiological, Clinical and Biological Profiles in the Cardiology and Internal Medicine Departments of the Mother-Child CHU "Luxembourg". World Journal of Cardiovascular Diseases, 11, 593-602.

https://doi.org/10.4236/wjcd.2021.1112056

Received: November 5, 2021

Accepted: December 18, 2021

Published: December 21, 2021

Copyright $\odot 2021$ by author(s) and Scientific Research Publishing Inc. This work is licensed under the Creative Commons Attribution International License (CC BY 4.0).

http://creativecommons.org/licenses/by/4.0/

(c) (i) Open Access

\begin{abstract}
Introduction: The metabolic syndrome is a clinical entity defined by the association in the same subject of four of the following five factors: abdominal obesity (or android), type 2 diabetes, hypertension, hypo HDL cholesterolemia, hypertriglyceridemia. The aim of the work was to study the epidemiological, clinical-biological profiles and complications of patients in the cardiology and internal medicine department of the Mother-Child CHU "Luxembourg". Materials and Methods: We carried out a cross-sectional study, from September 2019 to June 2020 in the cardiology and internal department of the mother-child CHU "Luxembourg". All patients with metabolic syndrome admitted to the two departments who agreed to participate during the study period were included in the study. These patients meet the 2009 harmonization attempt criteria (IDF 2009). The variables studied were: socio-demographic characteristics (sex, age, profession), pathological history, clinical signs (functional signs, BMI, waist size), paraclinical signs (ECG, cardiac ultrasound, laboratory assessment) and complications. Results: A total of 104 patients were included. The female sex represented $58.65 \%$ of cases. The 60 to 69 age group was the majority with $40.78 \%$, housewives occupied $41.34 \%$ of cases. Diabetes, arterial hypertension and dyslipidemia were the most represented cardiovascular risk factors with respectively: $80.77 \%$,
\end{abstract}


$79.81 \%$ and $53.85 \%$. Visual blurring was the most common functional sign with $23.08 \%$ of cases. Moderate obesity was observed in $34 \%$ of patients. Waist circumference was high in $39.53 \%$ of male patients and $37.70 \%$ of female patients. Cardiac ultrasound found a severely collapsed ejection fraction in $25 \%$ of patients. HDL-c levels were low in $64.52 \%$ of male patients and $75 \%$ of female patients. The most observed complications were: dyslipidemia (53.85\%), stroke and renal failure with $23 \%$ respectively. Conclusion: The metabolic syndrome remains a real public health problem, constantly increasing in our populations and constitutes a danger by its constituent elements.

\section{Keywords}

Metabolic Syndrome, Epidemiological Profiles, Clinical-Biological, CHUME, Luxembourg, Bamako

\section{Introduction}

Metabolic syndrome is a clinical entity defined by the association in the same subject of four of the following five factors: abdominal obesity (or android), type 2 diabetes, hypertension, hypo HDL cholesterolemia, hypertriglyceridemia. Heredity, a sedentary lifestyle and eating habits play a very important role in its development [1]. Metabolic syndrome significantly increases the risk of cardiovascular disease [2]. Since its initial description by REAVEN in 1988 under the term "syndrome X", the metabolic syndrome has continued to evolve and several definitions are currently proposed [2]. It is characterized by hyperinsulinism resulting from insulin resistance and a group of factors including hypertriglyceridemia, hypo HDL cholesterolemia, glucose intolerance, high blood pressure and android obesity [1]. The prevalence of metabolic syndrome is increasing rapidly in both developed and emerging countries as well as in developing countries. North American data from the latest NHANES III registry suggests that $20 \%-30 \%$ of adults living in the United States are affected by this syndrome [2]. The DESIR study [3] found an incidence of $16 \%$ in men and $11 \%$ in women and the MONICA study rates of $23.5 \%$ and $17.9 \%$, respectively, in France [4]. In 2015, KABA found in the internal medicine department of Conakry University Hospital a prevalence of 23\%, of which men represented 63\% [5] while MEHREZ observed $6.57 \%$ with a female predominance in a Senegalese population in 2017 [6]. In Mali, in 2008 TRAORE observed a prevalence of $12.5 \%$ with a clear female predominance of $76 \%$ in the internal medicine department of CHU POINT G [7]. BERTHE observed 68\% in the diabetic population of Bamako [8] in 2009. COULIBALY found $58 \%$ in a study carried out in 2015 [9]. The metabolic syndrome is a real public health problem because of its complications (cardiovascular and type 2 diabetes), the absence of data at the level of the Mother-Child University Hospital "Luxembourg" motivated us to carry out this work with the aim of studying the epidemiological, clinical-biological profiles and the related 
complications in the cardiology and medicine department at the Mother-Child University Hospital "Luxembourg” in Bamako.

\section{Materials and Methods}

This is a cross-sectional study, which took place from September 2019 to June 2020 in the cardiology and internal medicine department of the mother-child $\mathrm{CHU}$ "Luxembourg". Inclusion criteria: Were included in this study all patients with metabolic syndrome in the two departments who came in consultation or hospitalized who agreed to participate during the study period and who meet the criteria of the attempt to harmonize 2009 (IDF 2009). Patients with metabolic syndrome who did not meet the criteria of the 2009 harmonization attempt (IDF 2009) were not included in the study, as patients with metabolic syndrome did not agree to participate for a period of the study period. The data was collected from patient medical records collected on survey forms created using Epi info 7 software version 7.2.2.6. Informed consent was obtained with strict respect for confidentiality. The variables studied were (mixed): socio-demographic characteristics (sex, age, profession), pathological history, clinical signs (functional signs, BMI, waist size), para clinical (ECG, cardiac ultrasound, laboratory assessment) and complications. Epi info 7 version 7.2.2.6, Excel and Word software were used for data collection and analysis, the results presented in tabular and graphical form.

\section{Definitions of terms:}

HbA1C: Glycated hemoglobin

LDL cholesterol: Low density lipoprotein

HDL cholesterol: High density lipoprotein

Criteria of the 2009 harmonization attempt (IDF 2009):

The new definition of harmonization of the SM or IDF 2009 is based on the association in the same individual of at least 3 of the criteria mentioned in Table 1 below.

Table 1. Attempt to harmonize criteria for metabolic syndrome [22:24].

\begin{tabular}{ll}
\hline & 3 Necessary criteria \\
\hline Waist size & Increase defined by ethnicity \\
Triglycerides & $>1.50 \mathrm{~g} / \mathrm{l}$ or specific treatment for this lipid disorder \\
Arterial Pressure & $\geq 130 / 85 \mathrm{mmHg}$, or high blood pressure treated \\
High density lipoprotein cholesterol & $<0.40 \mathrm{~g} / \mathrm{l}$ (men); $<0.50 \mathrm{~g} / \mathrm{I}$ (women) \\
Fasting blood sugar & $\geq 1.10 \mathrm{~g} / \mathrm{l}$ \\
\hline
\end{tabular}

\section{Ethical Considerations:}

All patients give their verbal consent, being informed about the procedures in the study, their harmless character and even anonymous treatment of their data. 


\section{Results}

During this study, we identified 104 patients according to the 2009 harmonization attempt. The female sex occupied $58.65 \%$ of cases and the male sex $41.35 \%$ with a sex ratio $=0.70$

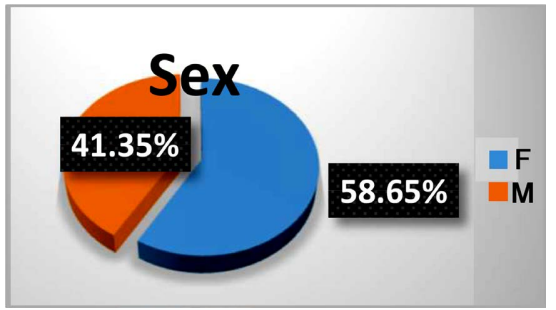

Figure 1. Distribution by gender.

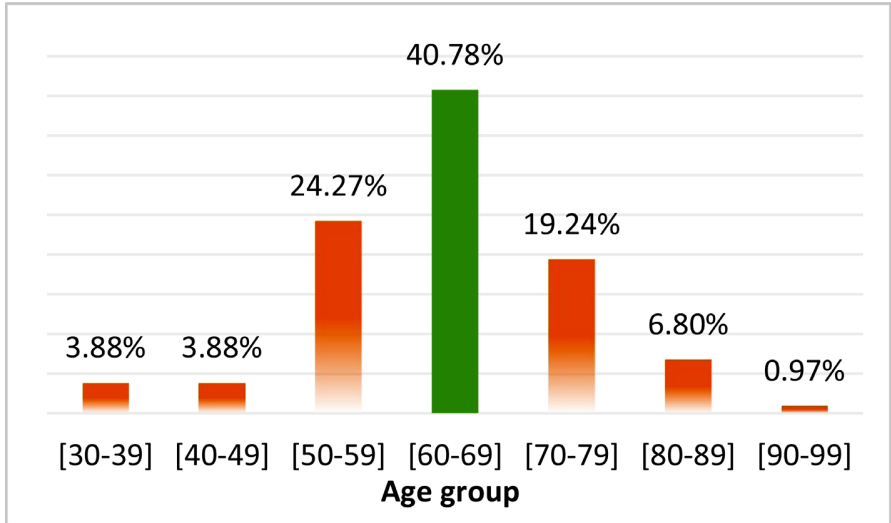

Figure 2. Distribution by age group.

The 60 - 69 age group accounted for $40.78 \%$. The average age was $63.00 \pm$ 11.44 years, with extremes ranging from 30 to 98 years.

Table 2. Distribution according to profession.

\begin{tabular}{ccc}
\hline Profession & N & $\%$ \\
\hline Trader & 11 & 10.58 \\
Consultant & 3 & 2.90 \\
Farmer & 4 & 3.85 \\
Commercial employee & 2 & 1.92 \\
Hygienist & 2 & 1.92 \\
Housewives & 43 & 41.34 \\
Professor & 1 & 0.96 \\
Retired & 16 & 15.38 \\
Sales woman & 2 & 1.92 \\
Others & 20 & 19.23 \\
Total & 104 & 100 \\
\hline
\end{tabular}

Source: Medical file. 
Housewives accounted for $41.34 \%$ of cases.

Table 3. Distribution according to personal history.

\begin{tabular}{ccc}
\hline Personal History & N & $\%$ \\
\hline Diabetes & 84 & $\mathbf{8 0 . 7 7}$ \\
HTA & 83 & $\mathbf{7 9 . 8 1}$ \\
Dyslipidemia & 56 & 53.85 \\
Stroke & 14 & 13.46 \\
Myocardial Infarction & 4 & 3.85 \\
Obliterating arteriopathy of the lower limbs & 8 & 7.69 \\
Drop & 5 & 4.81 \\
Smoking & 16 & 15.38 \\
Alcoholic & 5 & 4.81 \\
\hline
\end{tabular}

Source: Medical file.

Diabetes, arterial hypertension and dyslipidemia were the most represented risk factors with respectively: $80.77 \%, 79.81 \%$ and $53.85 \%$.

Table 4. Distribution according to functional signs.

\begin{tabular}{ccc}
\hline Clinical signs & N & $\%$ \\
\hline Visual blur & 24 & $\mathbf{2 3 . 0 8}$ \\
Dyspnea on exertion & 23 & $\mathbf{2 2 . 1 2}$ \\
Leg pain & 19 & 18.27 \\
Headache & 18 & 17.31 \\
Chest pain & 17 & 16.35 \\
Palpitations & 12 & 11.54 \\
Dizziness & 10 & 9.62 \\
Dyspnea at rest & 7 & 6.73 \\
Ringing in the ears & 7 & 6.73 \\
Sleep Apnea & 5 & 4.81 \\
Syncope & 2 & 1.92 \\
\hline
\end{tabular}

Source: Medical file.

Visual blurring was present in $23.08 \%$ of cases, followed by dyspnea on exertion with $22.12 \%$.

Moderate obesity was observed in $34 \%$ of patients and overweight in $31 \%$.

Waist circumference was high in $39.53 \%$ of the male patients with an average of $104 \pm 11.04 \mathrm{~cm}$ against $37.70 \%$ for the female patients (average $=100 \pm 15.22$ $\mathrm{cm})$.

Sinus rhythm in $55.77 \%$ of cases, cardiac ultrasound found a severely collapsed ejection fraction in $25 \%$ of patients, hyperglycemia accounted for $51 \%$, 


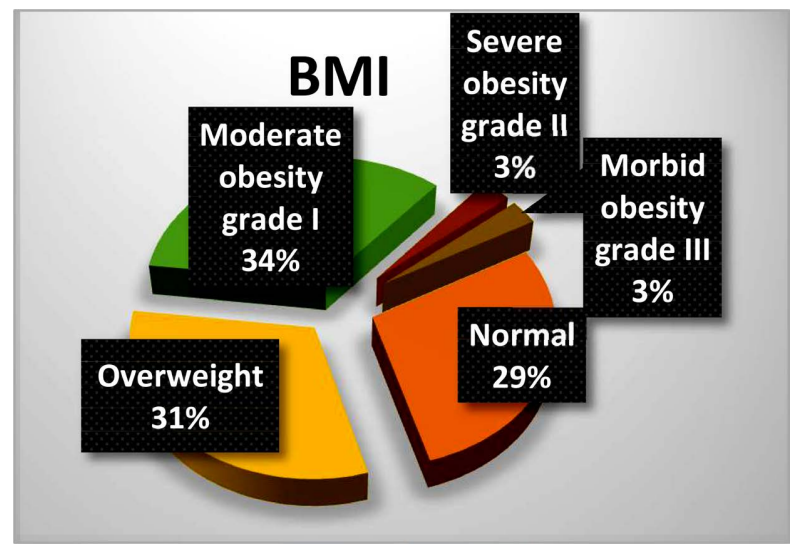

Source: Medical file.

Figure 3. Distribution according to BMI (body mass index) class.

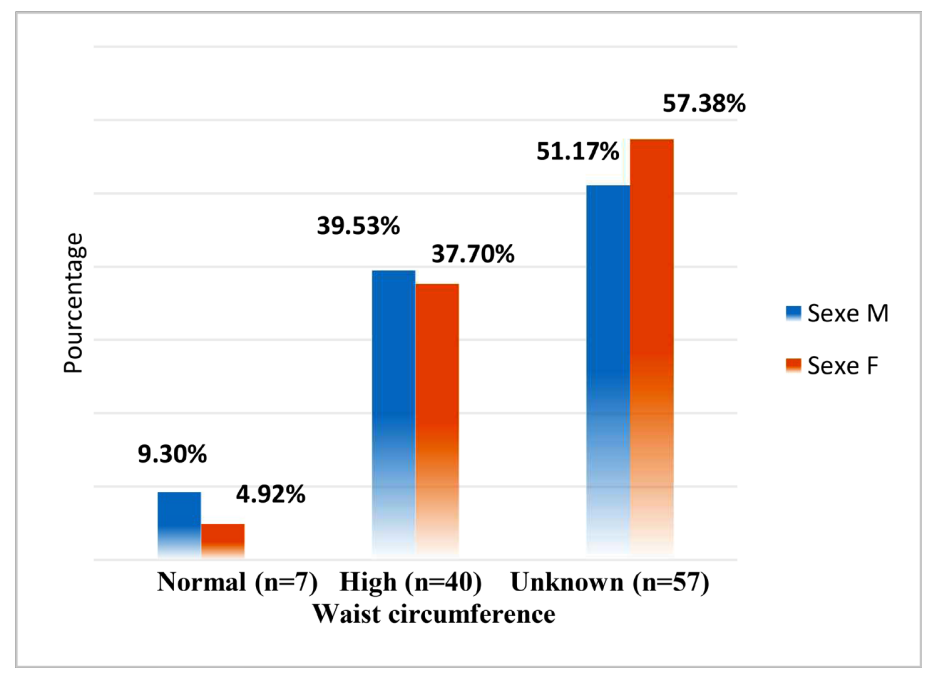

Source: Medical file.

Figure 4. Distribution according to waist circumference.

Table 5. Breakdown according to paraclinical examinations.

\begin{tabular}{lcc}
\hline Para clinical variables & N & $\%$ \\
\hline EKG & 58 & 55.77 \\
$\quad$ Sinus rhythm & 12 & 11.54 \\
Conduction disorder & 11 & 10.58 \\
Rhythm disturbance & & \\
Echocardiography & 71 & 68.00 \\
LVEF retained & 7 & 7.00 \\
Moderately collapsed LVEF & 26 & 25.00 \\
Severely collapsed LVEF & & \\
Fasting blood sugar & 53 & 51.00 \\
Hyperglycemia & 53 & \\
\hline
\end{tabular}




\section{Continued}

Hypoglycemia
Normal blood sugar
Blood sugar not achieved
Glycated hemoglobin

Not carried out

Normal HbA1C

Elevated HbA1C

\section{Lipidogram according to male patients}

Total Cholesterol

Low HDL-c level

Low LDL-c level

Hyper Triglyceridemia

Lipidogram according to female patients

Total Cholesterol

Low HDL-c level

Low LDL-c level

Hyper Triglyceridemia

7

20

22

7.00

20.00

22.00

48.07

23.08

28,85

30

12.90

64.52

16.13

41.94

44

15.00

4

75.00

19

18.18

45

Source: Medical file.

glycated hemoglobin was elevated in $29 \%$ of patients. The Lipidogram carried out in male patients found: a low HDL-c level in $64.52 \%$, hyper triglyceridemia in $41.94 \%$ of cases. The lipidogram of female patients showed: a low HDL-c level in $75 \%$ of cases, hypertriglyceridemia in $42.86 \%$ of patients.

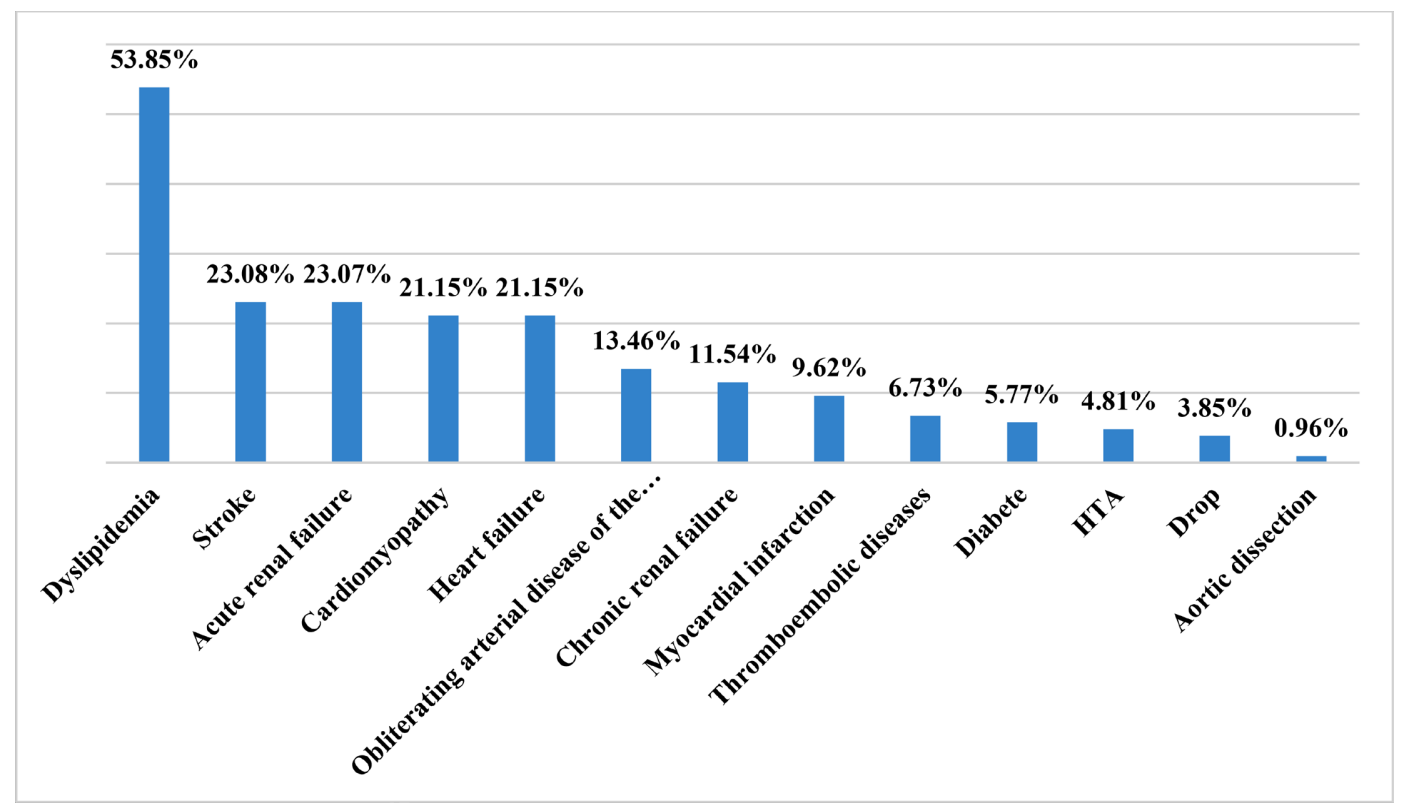

Figure 5. Distribution according to the main complications. 
Complications were dominated by dyslipidemia with a frequency of $53.85 \%$, followed by stroke and acute renal failure with a frequency of $23 \%$ each.

\section{Discussion}

A total of 104 patients were included, 61 women or $58.65 \%$ and 43 men or $41.35 \%$ (Figure 1), with a sex ratio of 0.70 . Our result is similar to that of Raharinavalona with a female predominance of $53.88 \%$ and a sex ratio of 0.86 [10] in a type 2 diabetic population (harmonization FID 2009), the same observation was made by Laraqui with a frequency of $21.7 \%$ [11]. The average age in our series was $63.00 \pm 11.44$ years, with extremes ranging from 30 to 98 years. The predominant age group was that of 60 to 69 years with a frequency of $48.78 \%$ (Figure 2). The same observation was made by BA in Senegal with an average age of 63.3 years [12], Alkassan found a lower result than ours with a frequency of $31.51 \%$ in the age group of 50 to 70 years [13]. This result is supported by numerous studies which show an increase in the prevalence of metabolic syndrome with age. Housewives were the most affected with a rate of $41.23 \%$ (Table 2 ). This situation is explained by the sedentary lifestyle led by women in general and in particular those who have no other activity than the household and by the lack of income to afford a healthier diet. The main antecedents found were: diabetes with $80.77 \%$, followed by hypertension $79.81 \%$ and dyslipidemia with $53.85 \%$ (Table 3). This result is slightly higher than that of Laraqui who observed a frequency of $12.8 \%$ [11]. Tobacco is defined in numerous studies as an important risk factor in the occurrence of cardiovascular events [3]. Visual blurring was present in $23.08 \%$ of cases, followed by dyspnea on exertion with $22.12 \%$ (Table 4). These clinical signs speak in favor of complications in the eyes and heart. In our series, $34 \%$ of our patients presented moderate obesity and $31 \%$ were overweight, either a cumulative rate of $71 \%$ above normal (Figure 3 ). Laraqui observed $53.4 \%$ of overweight patients [11]. Waist circumference was high in 39.53 of the male patients with an average of $104 \pm 11.04 \mathrm{~cm}$ against $37.70 \%$ for the female patients (average $=100 \pm 15.22 \mathrm{~cm}$ ) Figure 4 . These data remain consistently high in more than half of our patients. In our study, out of 41 patients who performed an ECG. $55.77 \%$ presented a sinus rhythm, an LVH was found in $4.81 \%$ which is predictive of some complications. $68 \%$ of patients with a cardiac ultrasound had retained LVEF. Hyperglycemia was found in 51\% of patients due to the fact that the majority of patients had diabetes as a history and did not follow an appropriate diet. Elevated glycated hemoglobin (HbA1C) levels were found in $29 \%$ of cases. Low HDL-c was the predominant dyslipidemia in patients of both sexes, $75 \%$ in women and $64.52 \%$ in men (Table 5). HDL-cholesterol has a vascular protective effect against the development of atherosclerosis. The FRAMINGHAM study was one of the first prospective studies to show the inverse relationship between HDL-cholesterol and cardiovascular disease [14]. The European PROCAM study also demonstrated a very significant decrease in coronary risk as the value of HDL-cholesterol increased, with a 
risk 3 times higher in subjects whose HDL-cholesterol was less than $0.35 \mathrm{~g} / \mathrm{l}$ than that of subjects whose level was greater than $0.35 \mathrm{~g} / 1$ [15]. Elevated triglyceridemia levels were observed in $42.86 \%$ of women and $41.94 \%$ of men (Table 5 ). Overall lipid abnormalities are observed more in women than in men, this situation could be explained by the sedentary lifestyle in women and especially by fleeing as age advances. In our series, complications were dominated by dyslipidemia with a frequency of $53.85 \%$ (Figure 5 ). This could be explained by the fact that they are the starting point of cardiovascular complications. Stroke and acute renal failure followed with a frequency of $23 \%$ each (Figure 5). Heart failure and cardiomyopathy were found in $21.15 \%$ of cases each (Figure 5). This result proves that the metabolic syndrome constitutes a true precursor in the occurrence of cardiovascular events and emphasizes the need to implement all means to prevent these complications.

\section{However, our study had many limitations, namely:}

- The small size of the sample.

- The difficulty of collecting anthropometric data in bedridden patients (unconscious and bedridden).

\section{Conclusion}

Metabolic syndrome is the combination of different metabolic and hemodynamic factors into a single entity that dramatically increases the risk of type 2 diabetes and/or cardiovascular disease. The female sex and the elderly are the most affected. Diabetes, hypertension, obesity and dyslipidemia are the most common personal histories. The metabolic syndrome remains a real public health problem, constantly increasing in our populations and constitutes a danger both in terms of its constituent elements and its complications. Its management primarily involves prevention through adopting a healthy lifestyle and treating people at high risk.

\section{Acknowledgements}

Thanks to the University Hospital of Mother and Child "Luxembourg" of Bamako, Mali.

\section{Conflicts of Interest}

The authors declare no conflicts of interest regarding the publication of this paper.

\section{References}

[1] Tison, E. (2005) Syndrome métabolique: Diagnostic, conséquences cardiaques et vasculaires. EMC-Cardiologie-Angéiologie, 2, 423-430.

https://doi.org/10.1016/j.emcaa.2005.09.001

[2] Lameira, D., Lejeune, S. and Mourad, J.J. (2008) Le syndrome métabolique: Son épidémiologie et ses risques. Annales de Dermatologie et de Vénéréologie, 135, 249-253. https://doi.org/10.1016/S0151-9638(08)70543-X 
[3] Balkau, B., Vernay, M., Mhamdi, L., et al. (2003) L'incidence et la persistance du syndrome métabolique NCEP (National Cholestérol Education Program). L'étude française DESIR. Diabetes \& Metabolism Journal, 29, 526-532. https://doi.org/10.1016/S1262-3636(07)70067-8

[4] Dallongeville, J. (2007) Epidémiologie du Syndrome Métabolique et du risque cardiovasculaire. Epidémiologie et Santé Publique. Institut Pasteur de Lille: INSERM U744-LILLE.

[5] Kaba, M.L., Sinayoko, M., Touré, A., et al. (2016) Profil épidémiologique et clinique des patients atteints de syndrome métabolique dans un service de médecine interne à Conakry. Néphrologie \& Thérapeutique, 12, 408. https://doi.org/10.1016/j.nephro.2016.07.133

[6] Mehrez, A. (2017) Prévalence du syndrome métabolique dans une population sénégalaise [mémoire biologie clinique]. Université Cheik Anta Diop, Dakar, No. 336.

[7] Traore, A. (2008) Prévalence du Syndrome Métabolique dans le service de médecine interne du point $\mathrm{G}$ [thèse de médecine]. Université des Sciences, des Techniques et des Technologies de Bamako, Bamako, No. 08M294.

[8] Brehima, B. (2009) Etude de la prévalence du syndrome métabolique dans la population diabétique de Bamako et l'influence du régime alimentaire et de l'activité physique dans la prise en charge de ces patients [Thèse de médecine]. Université des Sciences, des Techniques et des Technologies de Bamako, Bamako, No. 09 M394.

[9] Coulibaly, S.M. (2015) Les complications cardiovasculaires au cours du syndrome métabolique [thèse de médecine]. Université des Sciences, des Techniques et des Technologies de Bamako, Bamako, No. 15M277.

[10] Raharinavalona, S.A., Razanamparany, T., Raherison, R.E., et al. (2020) Prévalences du syndrome métabolique et des facteurs de risque cardiovasculaire chez les diabétiques de type 2 vus au service d'endocrinologie, Antananarivo. The Pan African Medical Journal, 36, 67. https://www.ncbi.nlm.nih.gov/pmc/articles/PMC7380865 https://doi.org/10.11604/pamj.2020.36.67.15845

[11] Laraqui, O., Laraqui, S., Manar, N., et al. (2017) Dépistage et prévalence des principaux composants du syndrome métabolique chez les professionnels de soins au Maroc/Screening and Prevalence of the Main Components of the Metabolic Syndrome among Health Care Workers in Morocco. International Journal of Innovation and Applied Studies, 20, 863.

[12] Ba, F.G. (2012) Le syndrome métabolique: Etude multicentrique descriptive en milieu hospitalier cardiologique dakarois [Thèse de médecine]. Université Cheikh Anta Diop, Dakar, No. 170.

[13] Alkassan, Y. (2019) Syndrome métabolique et pathologies rhumatismales: Etude de330 observations [Thèse de médecine]. Université Cheikh Anta Diop, Dakar, No. 121.

[14] Castelli, W.P., Garrisson, R.J., Wilson, P.W., et al. (1986) Incidence of Coronary Heart Disease and Lipoprotein Cholesterol Levels. The Framingham Study. JAMA, 256, 2835-2838. https://doi.org/10.1001/jama.256.20.2835

[15] Assmann, G., Cullen, P. and Schulte, H. (1998) The Munster Heart Study (Procam). Result of Follow-Up at 8 Years. European Heart Journal, 19, 2-11. https://doi.org/10.1053/euhj.1998.1086 